\title{
Are Social Networks Survival Networks? An Example from the Late Pre-Hispanic US Southwest
}

Lewis Borck • Barbara J. Mills •

Abstract Archaeologists have regarded social networks as both the links through which people transmitted information and goods as well as a form of social storage creating relationships that could be drawn upon in times of subsistence shortfalls or other deleterious environmental conditions. In this article, formal social network analytical (SNA) methods are applied to archaeological data from the late preHispanic North American Southwest to look at what kinds of social networks characterized those regions that were the most enduring versus those that were depopulated over a 250-year period (A.D. 1200-1450). In that time, large areas of the Southwest were no longer used for residential purposes, some of which corresponds with welldocumented region-wide drought. Past research has demonstrated that some population levels could have been maintained in these regions, yet regional scale depopulation occurred. We look at the degree to which the network level property of embeddedness, along with population size, can help to explain why some regions were depopulated and others were not. SNA can help archaeologists examine why emigration occurred in some areas following an environmental crisis while other areas continued to be inhabited and even received migrants. Moreover, we modify SNA techniques to take full advantage of the time depth and spatial and demographic variability of our archaeological data set. The results of this study should be of interest to those who seek to understand human responses to past, present, and future worldwide catastrophes since it is now widely recognized that responses to major human disasters, such as hurricanes, were "likely to be shaped by pre-existing or new social networks" (as reported by Suter et al. (Research and Policy Review 28:1-10, 2009)).

Keywords Social network analysis $\cdot$ E-I index $\cdot$ Migration $\cdot$ Resilience $\cdot$ Salado .

L. Borck $(\bowtie) \cdot$ B. J. Mills

School of Anthropology, University of Arizona, Tucson, AZ 85721, USA 


\section{Overview}

Independence? That's middle-class blasphemy. We are all dependent on one

An enduring archaeological problem is why some regions were depopulated while inhabitants remained in other areas for centuries and even millennia. When depopulation is sudden and arises at large spatial scales, it has often been called "collapse." We place this term in scare quotes because it has been interpreted to mean cultural discontinuity - such as the Hohokam or Chaco "collapse" in the US Southwest or the "collapse" of the Maya in Central America-without considering continuities in indigenous populations through processes such as migration and decentralized social reorganizations (see also the many critiques of the term, e.g., Hegmon et al. 1998; McAnany and Yoffee 2010; Middleton 2012; Wilcox 2009). When an entire region is depopulated, it frequently entails large-scale migrations. The underlying reasons for these demographic shifts from one area to another have been central to understanding human history across the globe (e.g., Anthony 1990; Cameron 2013).

Another way to approach the problem is to look at why and how people are able to persist in some regions over long periods. What makes settlements in these regions more successful than others? Persistence may also be associated with the concept of resilience (Holling and Gunderson 2002; Holling 1973; Redman 2005) because communities that endure have withstood threats to their ongoing sustainability. However, in some situations, persistence may be maladaptive rather than adaptive. For example, generational residential mobility can enhance the resilience of particular individuals and groups (Varien 1999). Staying in one place may not be the best decision because of negative changes in local, social, or environmental contexts. Nonetheless, migrations are expensive and disruptive to the existing social order and often result in migrants having lower status than the groups they join (Mills 2007).

In a recent review of archaeological approaches to "collapse" and resilience, Guy Middleton (2012) suggests that too much emphasis has been placed on environmental factors at the expense of social factors (e.g., Diamond 2005). Archaeologists working in the US Southwest - where a high-resolution paleoclimatic record indicates long-term periods of drought - have recognized that climatic downturns are not sufficient explanations for depopulation and migration (Kohler 2010; Minnis 1985; Van West 1994; Wright 2010). As Glowacki (2010, p. 200) pointed out "[c]omplete regional depopulation is not a predestined outcome of drought and poor agricultural yield." Van West (1994; see also Ahlstrom et al. 1995 and Billman et al. 2000) demonstrated that, despite the regional depopulation, yields could have sustained some of the population in the Mesa Verde region during the drought of the last quarter of the thirteenth century, albeit at lower levels. Other scholars have highlighted the increased incidence of violence during periods of drought, especially during the early twelfth and late thirteenth centuries (e.g., Kuckelman et al. 2002; Kuckelman and Martin 2012). Kohler (2010) suggested that the crosscutting social institutions that were created after the eleventh century, which enabled the integration of segmentary groups with high residential mobility, produced societies that could no longer easily fission when mobility and social flexibility was required in later periods. These religious institutions 
would have facilitated intra-regional interaction while at the same time, they may have 83 laid the ground work for future inter-regional conflict and factionalism (Glowacki 2010; Kaldahl et al. 2004).

What the above Southwestern examples share is an emphasis on the formation, transformation, and/or dissolution of different kinds of social networks. They also largely focus on specific regions. Another way of incorporating social factors into models of regional depopulation is to understand these areas in the context of interregional networks (Mills et al. 2013a, b, c). As Hill and his colleagues (2010) pointed out regarding the depopulation of the Mesa Verde area, this region can only be understood by looking at population changes at much larger scales (see also Duff 1998). Several previous examples from the northern Southwest illustrate the value of looking at migration across regional boundaries and tie these, either explicitly or implicitly, to large-scale social networks. The intensity and extent of social networks has been widely acknowledged in the anthropological literature as providing access to information and resources to minimize risk and uncertainty (Colson 1979; DysonHudson and Smith 1978; Halstead and O'Shea 1989; Wiessner 1977). This is particularly the case in the literature on foragers but it also pertains to agriculturalists in a setting of high environmental variation, such as is found in many periods in the North American Southwest. These authors argue that access to information and resources from diverse environments can help populations deal with unpredictability. Importantly, the work of Cordell and colleagues (2007) and Rautman (1993) suggest that the distance and direction of such external connections are important in understanding how social networks were used to integrate diverse groups. This prior work also shows the importance of inter-regional social networks in creating pathways for future migration.

In this paper, we investigate several aspects of Southwest regions to better understand the social factors that, during A.D. 1200-1450, led to regional depopulation on the one hand and regional persistence on the other. We argue that the application of social network analysis (SNA) to archaeological data provides insights into the ways in which interaction at multiple scales (or lack thereof) can explain regional depopulation or persistence. We use SNA to look at both internal and external ties to understand the social component of regional depopulations as well as to examine how long-distance ties created viable alternatives to staying in place. We argue that regions with relatively low population sizes and relatively closed social networks were especially vulnerable to depopulation. Those regions with relatively open social networks, or closed networks and large population sizes, were more successful through time.

\section{Social Networks and Regional Depopulation}

SNA refers to a broad range of methods and models, originally derived from the mathematical field of graph theory, for formally exploring the structure of relations among some set of social actors (Wasserman and Faust 1994). The most common means for analyzing and visualizing social networks involves producing network graphs where actors (which can be individuals or larger groups/organizations) are depicted as nodes and the social relationships among these actors are depicted as lines 
or topology of a network (e.g., its size or density), to understand differences among nodes (e.g., their centrality), and to look at the dynamics of networks over time (Carrington et al. 2005; Newman et al. 2006; Newman 2009; Scott 2000; Wasserman and Faust 1994). The applications of SNA in the social sciences are quite diverse, but are linked through a general relational approach in which the nature and structure of interactions among a set of actors is essential to understanding the outcomes for those actors and the distribution of resources (social or other forms of capital) across a network (e.g., Saunders 2007; Somers 1994).

Our article uses data from the western US Southwest during the late pre-Hispanic period (A.D. 1200-1450). This is a broad region incorporating a number of archaeologically documented areas including those attributed to Ancestral Pueblo in the north and Hohokam in the south. The period is characterized by increasing aggregation or coalescence over time, the depopulation of many areas, and concomitant large-scale migrations (Hill et al. 2004). Another important feature of the period is a major drought from A.D. 1276 to 1299 that is often cited as one of the causes for the depopulation of the northern Four Corners. However, the extent to which this drought explains the depopulation has been debated (Kohler 2010; Minnis 1985; Van West 1994; Wright 2010). Current research suggests that there may have been migrations out of the Four Corners beginning at least two decades before the drought and that this process likely continued through the last half of the thirteenth century (e.g., Wright 2010).

In this article, we explore one particular aspect of network structure known as embeddedness. Specifically, we examine how the degree of embeddedness of network actors (defined as individual archaeological settlements) and population size correlate with population stability (persistence) and instability (depopulation and emigration). Recent research demonstrates that one way that people are able to cope with disasters is by using their social networks to access external help and resources (McMahan 2013; Suter et al. 2009). We use SNA to look at the relational characteristics of those regions that were depopulated as well as those regions where populations endured despite environmental downturns, to examine how the overall embeddedness of a network's structure can affect how populations react to environmental and social stresses. To compute the embeddedness of a region, we use the external-internal (E-I) index (Krackhardt and Stern 1988). This measure quantifies network relations at three scales: population (the entire network), region (sub-sets of the network).

\section{Interpreting the External-Internal Index: Homophily and Embeddedness}

The E-I index, which is fully defined in the proceeding methods section, essentially quantifies the relational structure within and between groups (Everett and Borgatti 2012; Krackhardt and Stern 1988; Krackhardt 1994). It has been variously described as analogous to homophily (Borgatti et al. 2002; Everett and Borgatti 2012) and the trend for people to connect with others similar to themselves as well as embeddedness (Hanneman and Riddle 2005) or how connected a node or group of nodes is to the network.

Homophily is one of the most pervasive and robust tendencies of human interaction, describing how people tend to seek out and interact with others that are the most like them-often characterized as "birds of a feather" (see McPherson et al. 2001 for a 
survey). As a mechanism of social relations, it can explain group composition in terms of social identities ranging from ethnicity to age (Lazarsfeld and Merton 1954). In fact, ethnicity, along with geography and kinship (McPherson et al. 2001, p. 422), has been demonstrated to be one of the main motivating factors behind homophilous practices. Everett and Borgatti are among the researchers who treat the E-I index as a measure of homophily and heterophily, where smaller values (internal connections) indicate greater homophily and larger values (external connections) indicate lesser homophily or greater heterophily. The E-I index as a measure of homophily is essentially quantifying the propensity of individuals to interact with similar actors (Burt 1991; Laumann 1966; Lazarsfeld and Merton 1954; Marsden 1988; McPherson et al. 2001; McPherson and Smith-Lovin 1987; Verbrugge 1977). Finally, the E-I index is an attractive gauge of homophily because it is not dependent on the density of a network (Everett and Borgatti 2012, p. 562).

While a related notion, embeddedness is discrete from homophily. Embeddedness is an indicator of how a particular individual or social group will socially interact by either choosing to network with many other individuals or only a few. Embeddedness is also inherently spatial (Martin 1994) because of tendencies toward spatial propinquity (Allen 1977; Krackhardt 1994), which argues that people who are physically closer together tend to interact and form stronger relationships. Embeddedness has been critiqued as a vague concept (see overview in Hess 2004) as originally used to describe how economic interactions in non-market economies were embedded within social relations (Polanyi 2001). This concept has since been reexamined and productively explored in multiple arenas (Brass et al. 2004; Gimeno 2004; Granovetter 1985; Uzzi 1996, 1997).

Hess (2004), while attempting to disentangle and clarify the concept of embeddedness, notes that there are three main ways of examining it: societal, network, and territorial. These three forms of embeddedness are strongly interrelated (Hess 2004) and depend primarily on how the data are acquired. Moreover, Hess argues that embeddedness is not a static measure, but a dynamic process (Hess 2004, p. 182). Although Hess is heavily reliant on biological analogies, specifically, the philosophical rhizome concept, to make his point, we feel that the overarching examination of embeddedness as a spatial-temporal process incorporating formation and change of social structures through time and space is robust. Thus, the E-I index, as a measure of embeddedness, quantifies how a particular group is likely to interact with its neighbors at a given point in time and how that may affect the network and actors during later temporal intervals. This dynamic and process-oriented definition of embeddedness is well suited to the application of diachronic data from the archaeological record.

These two interpretations of the E-I index, either as an indicator of embeddedness or homophily, are not simply variations of the relative frequency of within- or betweengroup ties, but are based on the temporal nature of a given data set. Specifically, we treat homophily as a micro-scale (nodal) attribute for a specific point in time (Fig. 1 illustrates the difference between embeddedness and homophily). Embeddedness can be examined at the meso (region) and macro (network) scales. Embeddedness, then, is a spatial-temporal process, as opposed to a synchronic trait, which is foundational to understanding how groups, in our case defined regionally, are likely to interact with their neighbors at a given point in time and how this will affect the shape of the entire network in the future. Embedded networks are externally oriented and infused with 


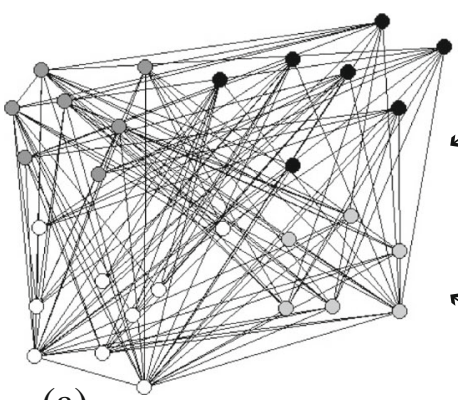

(a)

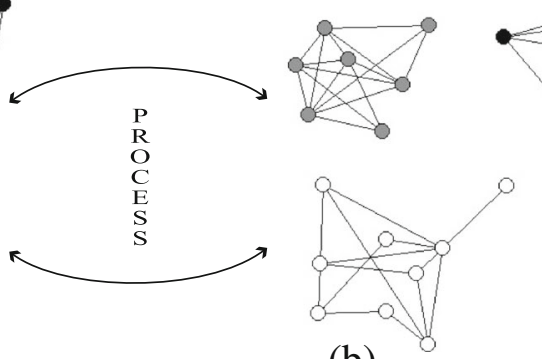

(b)

Fig. 1 Embeddedness in networks. Networks demonstrating a high degree of embeddedness (a) and disembeddedness (b). Changing nodal traits of either heterophily or homophily will determine if a network becomes more or less embedded. Specifically, heterophily (drive to interact with those different from you) will embed nodes and groups in a network whereas homophily (drive to interact with those similar to you) will disembed nodes and groups from a network

crosscutting relationships whereas disembedded networks are internally oriented and riddled with disjunctures, which impede the spread of information (Golub and Jackson 2012, p. 1317). The process of embeddedness or disembeddedness, of increasing external and internal interactions, is driven by heterophily and homophily, respectively. Heterophily and homophily have primarily been measured using synchronic data, but are likely processes as well-best looked at over time.

At its extreme, a fully disembedded network ${ }^{1}$ could conceivably create a terrarium effect (Fig. 1b), fundamentally containing the spread of any social invention or innovation. Conversely, increasing heterophily (higher E-I indices) through time creates an increasingly embedded network. Since behavior is rooted in networks of interpersonal relations, an examination of the structure of these interpersonal relations (for this study, we use the E-I index) provides insight into behavioral patterns (homophily/heterophily). An examination of the changing structure of these interpersonal relations creates insights into behavioral processes (embeddedness/ disembeddedness), something that can only be examined with diachronic data.

\section{The Southwest Social Networks Project Database}

In this study, we explore the changing nature of social relationships within and between regions using archaeological data from the Southwest Social Networks (SWSN) project. The SWSN project (Mills et al. 2013a, b, c, 2015; Peeples and Haas 2013; Peeples et al. 2014) is a large-scale interdisciplinary and collaborative effort that focuses on investigating broad patterns of interactions in the North American Southwest through formal SNA. The project database contains information on site size, location, habitation period, ceremonial architecture, ceramic types and counts, and obsidian counts and sourcing provenance for a large number of late pre-Hispanic (A.D. 1200-1550) sites across most of the US Southwest west of the Continental Divide. This project builds on the earlier Coalescent Communities Database (Hill et al.

\footnotetext{
${ }^{1}$ As opposed to a fully disconnected network, which would just be a series of nodes with no relationships or edges.
} 
2004, 2012; Wilcox et al. 2003), which contains site size and occupation information on a large proportion of documented settlements with more than 12 rooms across the US Southwest and portions of northern Mexico for the late pre-Hispanic and early colonial periods (ca. A.D. 1200-1700). Ceramic data, the basis of the analyses presented here, include painted and plain ceramic types and ware counts, and associated metadata, from more than 700 sites. These ceramic data were compiled from published and unpublished sources, reanalysis of museum collections, and infield archaeological analysis. The sum total of this database, containing information on over 4.3 million ceramic artifacts, represents the massive amount of archaeological work that was carried out over more than a century in the US Southwest.

For the purposes of the analyses presented here, we focus on sites with decorated ceramic ware frequency data for the period A.D. 1200-1450. In the US Southwest, ceramic wares are broad categories defined on similarities in design, materials, and manufacturing technology and which often have geographically restricted distributions. Ceramic wares often include smaller designations, known as types, which represent finer stylistic designations marked by shorter intervals of use and consumption. We rely on wares since they capture regional variation, but are more resistant to inconsistencies in recording among observers (Mills et al. 2013c, pp. 183-184; Peeples and Haas 2013, p. 236). Further, we focus specifically on decorated (painted) ceramic wares since these categories of ceramics are more often publicly used and consumed and more likely to be exchanged over long distances (see Duff 2002; Peeples 2011). We argue that similarities in the proportions of decorated ceramics present at pairs of sites in our database provide an indication of the probability of interaction among those sites.

A number of past studies demonstrating differences in the circulation and production of ceramics in the Southwest suggest that similarities in ceramic assemblages can result through a number of related processes including exchange, emulation, migration, and active signaling of social boundaries (Mills and Crown 1995; Stark and Heidke 1998). We contend that the similarities in the proportions of these various ceramic wares provide an indication of the most robust patterns of interaction based on all of these social processes and likely others. We do not claim that a high level of similarity necessarily implies direct interaction between the inhabitants of two sites, but rather that interaction was more likely and more frequent between pairs of sites marked by similar patterns of ceramic production and discard than between pairs of sites with quite different ceramic use and discard patterns (Mills et al. 2013b). Our use of ceramic similarities is therefore based on ceramic consumption patterns. More specifically, it reflects the choices made by residents of different settlements as to how they prepared and served various foods and beverages - the major uses of decorated ceramics (Mills et al. 2015).

For the analyses presented here, we define the nodes in our network as the sites in our database with systematic decorated ceramic ware counts. To study dynamic processes with our data set, the first step is to divide the ceramic ware counts into temporal snapshots representing ceramics likely deposited during each defined interval in which people lived at a site. Following methods developed by Roberts and others (2012; see also Mills et al. 2013a, c; Peeples and Haas 2013), the decorated ceramic data for each 
site were apportioned into five 50-year intervals between A.D. 1200 and 1450. In short, this apportioning procedure takes into account the date ranges of inhabitation at a site, the date ranges for each ceramic type, and the estimated population of each site using room counts (based on Hill et al. 2004). The apportioning method assumes a normal consumption curve for each type through time to estimate the proportion of each ceramic type deposited in each interval in which the site was inhabited.

Once the ceramic assemblages are apportioned, a matrix of similarities was generated for every pair of sites for which we have ceramic data for each 50year interval. These similarities are based on the relative percentages of all apportioned wares. To define the scale of similarity among sites, we use a rescaled version of the Brainerd-Robinson coefficient (following Mills et al. 2013a; Peeples and Roberts 2013) where the similarity $(S)$ between sites $a$ and $b$ is defined as:

$$
S_{a b}=\frac{200-\sum_{k}\left|P_{a k}-P_{b k}\right|}{200}
$$

where $k$ is all decorated ceramic wares, $P_{a k}$ is the percent of the ware $k$ at site $a$, and $P_{b k}$ is the percent of ware $k$ at site $b$ (Brainerd 1951; Robinson 1951). This measure normally ranges between 0 and 200 , but for this study, we divide these scores by 200 (the maximum possible similarity, $100+100 \%$ ) so that they range between 0 (no similarity) and 1 (perfect similarity). This procedure is common in many recent archaeological network analyses (Golitko et al. 2012; Hart and Engelbrecht 2012; Mills et al. 2013a, c; Peeples and Haas 2013; Peeples 2011). Rather than defining ties above or below some threshold similarity value as either present or absent, we interpret the raw similarity scores between pairs of sites as the weights of all relations between pairs of sites (see Opsahl et al. 2010; Peeples and Roberts 2013), which is to say the ties are created from continuous instead of binarized data. The relations are undirected. We make no assumptions regarding the directionality of influence or interaction between nodes. This procedure results in a symmetric matrix of similarity for each 50-year interval where the strength of relations between every pair of sites is indicated by a value from 0 to 1 .

Using the matrices of similarity for each 50-year interval described above, we then calculated a modified version of the external-internal (E-I) index. In order to calculate an E-I index at the population, region, and site live, it is necessary to partition nodes into groups based on independent criteria. For the purposes of this study, we defined 24 groups (Fig. 2), based on both conventional archaeological boundaries (see Duff 1998) and geographical features such as drainages (Mills et al. 2013b, p. 1; Peeples and Haas 2013 , p. 236). Only 22 regions have data covering the period analyzed in this paper. The creation of these regions is necessary in order to calculate the E-I index at the population, regional, and site level. Geographical boundaries such as these are often 


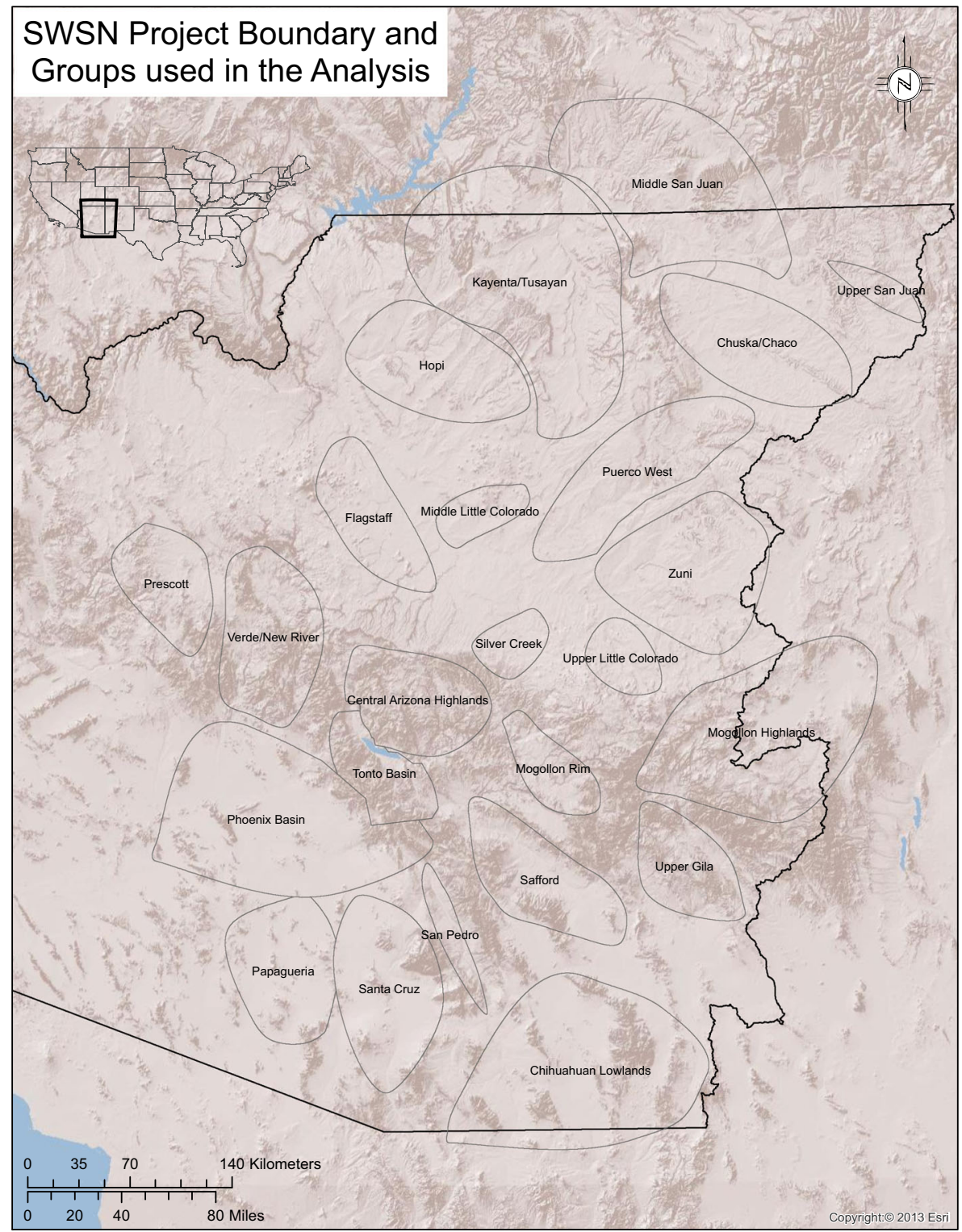

Fig. 2 Project boundaries and locations of regions. Regions used to define groups for this analysis. The Southwest Social Network database includes site location information beyond the limits of the project boundary so some regional boundaries extend beyond the project boundary. Systematic ceramic tabulations are only present within the project boundary however and these tabulations supply the data for the calculations in this article

an analytical decision that is consistent with network method and theory. Consequently, the E-I index, as we calculate it here, provides an indication of the relative frequency and strength of local (within-group) and more distant (between-group) ties.

The E-I index, as developed by Krackhardt and Stern (1988), has been implemented in the UCINET software package (Borgatti et al. 2002) and recently explored by 
Everett and Borgatti (2012) using calculations based on binarized network data. In other words, this measure requires that a tie between every pair of sites be strictly defined as either present (1) or absent (0). The E-I index is defined as:

$$
\frac{\text { External }(E)-\text { Internal }(I)}{\text { External }(E)+\text { Internal }(I)}
$$

where $E$ represents the count of external connections to nodes (for us archaeological residential sites) outside of the region and $I$ represents the number of internal connections within the region. This is calculated on site level data. Group level data is calculated by summing the E-I index of each node within a particular group, in this case the regions (see Fig. 2), divided by the number of sites in a particular region. The population level E-I index is then a sum of the E-I index of all regions within the database, divided by the number of regions. The resulting index score ranges from a low value of -1 (all of the ties of a region's settlements are only to other settlements within that region) to a high value of 1 (all settlements in a region are only connected to settlements in an external region). Values of 1 are obviously rare as they indicate a connection only with non-group members. Values of --1 are even rarer because there are frequently far more settlements outside of one's particular region than inside of it. Regions that have dramatic environmental restrictions that restrict where humans can settle, such as islands, would reverse this trend. An E-I index score of zero is the result of equal in-group and out-group connections.

For the purposes of the analyses presented here, we developed and implemented a variant of the E-I measure designed to be used with weighted, non-binarized network data in the open source R platform. The formula for calculating this index is identical to that above except that $E$ is instead defined as the total weight of external connections (sum of the weights of all external ties) and $I$ is defined as the total weight of all internal connections. This weighted measure allows us to consider both the number and strength of connections driving patterns of external or internal interaction.

Additionally, Everett and Borgatti (2012) note that when there are dramatic differences in the numbers of nodes among different groups, it is important to normalize E-I scores. In other words, if there are far more external ties possible than internal ties, we might expect values to tend toward external values unless we take the variable number of nodes among groups into account. Everett and Borgatti (2012) recommend normalizing by dividing $E$ and $I$ by the theoretical maximum possible number of external and internal ties before calculating the index. Because of the structure of our weighted data based on a symmetric similarity matrix, it is often not possible to obtain the theoretical maximum value that can be defined for binary networks based on similarity. Thus, we alter this procedure and normalize by dividing $E$ and $I$ by the maximum observed value for each as follows:

$$
\frac{\left(\frac{E}{\max (E)}\right)-\left(\frac{I}{\max (I)}\right)}{\left(\frac{E}{\max (E)}\right)+\left(\frac{I}{\max (I)}\right)}
$$

Standardizing by the maximum observed $E$ and $I$ values in this way is preferable, especially for our dataset, because it takes the total distribution and frequency, of ties 
into account, as well as their frequency at each temporal interval. Further, the maximum observed value can vary considerably between time periods based on the distribution of sites and the average weights of ties between those sites.

Finally, as a point of comparison, we also calculated the E-I index using the Krackhardt and Stern method using binary (presence/absence) ties. In order to do this, we created binary networks by defining all pairs of sites characterized by a similarity score of at least 0.75 (75\% of ceramic ware counts in common) as present (1) and all weaker connections as absent (0; see Mills et al. 2013a). Although it is almost always preferable to rely on non-binarized data where possible (Peeples and Roberts 2013), the comparison of E-I indices for continuous (weighted) and binary networks allows us to identify differences in external and internal relations based on comparisons of the strongest ties (binary data) against the combined sum of the weaker and stronger ties (non-binary data), which can serve to highlight the importance of the weaker ties. Lastly, the R scripts used to calculate the standard and normalized E-I indexes can be found at http://www.archaeologysouthwest.org/pdf/e-i_index_script.txt.

\section{Social Relationships and Crisis: Applying the External-Internal Index}

The population scale analysis is calculated for each temporal interval (Table 1). This analysis contains E-I indices calculated on both binarized and non-binarized data. The expected value is calculated by taking the average of 5000 random permutations at each of the five temporal intervals for which our data has been apportioned. These permutations are created by randomly assigning sites into regions based on the total frequency of each region in the actual sample (i.e., assigning groups at random without replacement). The probability indicates the likelihood that the observed E-I index could be produced by chance given the overall distribution of regions and similarity scores. As is readily apparent in Table 1, given a random distribution, the entire network is always strongly externally focused (positive values). This indicates we should expect high levels of heterophily and network level embeddedness, regardless of which 50-year interval we examine.

Deviations from this expected value are interesting in that they indicate a social or spatial cause that goes beyond pure graph theory. In fact, researchers argue that social

Table 1 Results of E-I index calculated on the entirety of the data used in this analysis through five periods

\begin{tabular}{llllll}
\hline & 1200 & 1250 & 1300 & 1350 & 1400 \\
\hline Total edges & 3257 & 3217 & 783 & 1521 & 256 \\
Non-binarized E-I & 0.221 & 0.450 & 0.539 & 0.691 & 0.581 \\
Binarized E-I & -0.189 & -0.060 & 0.085 & 0.517 & 0.514 \\
Expected & 0.786 & 0.849 & 0.868 & 0.865 & 0.736 \\
$p<$ & 0.0005 & 0.0005 & 0.0005 & 0.0005 & 0.0005
\end{tabular}

\subsection{5}

0.0005

0.0005

0.0005 
processes will generally cause networks to tend toward a higher proportion of internal relationships (e.g., McPherson et al. 2001). This will create a network that contains a number of densely intra-connected regions that are sparsely inter-connected (Fig. 1) and thus disembedded at the population level. This is actually the opposite of what is observed at most temporal intervals in the late prehispanic American Southwest (Table 1).

While homophily, the propensity to associate with similar actors or to have more internal than external relationships, has been repeatedly demonstrated in static data, our longitudinal data suggests a different trend, one which exhibits the process of embeddedness, the population level result of increasing heterophily, occurring over time. In fact, this increase through time of a network's level of embeddedness (Table 1) occurs regardless of whether the network is calculated on binarized (strong ties only) or non-binarized (strong and weak ties) data.

Of additional interest are the differences between the non-binarized $\mathrm{E}-\mathrm{I}$ index and the binarized E-I index (Table 1). The binarized E-I index, indicative of only the strongest ties in this network, does not become intensely externally focused until after the A.D. 1300-1350 period, following massive depopulation and migration out of several regions in the northern part of our study area (such as the Kayenta and Chaco/ Chuska regions). This fits with the available archaeological data that communities in the southern portion of our project area were involved in the widespread localized production of polychrome ceramics (Roosevelt Red Ware), which have been argued to signify the spread of an inclusive ideological movement called Salado (Crown 1994; Dean 2000; Haury 1976; Lekson 2002; Lyons 2003; Mills et al. 1999). Moreover, the balanced internal and external focus at the third period (Table 1: A.D.1300-1350) contrasts with the internal focus during the prior two periods (Table 1: A.D. 12001300). This reveals a pattern in which, at the population level, stronger ties were more important for creating internal connections, whereas weaker ties were crucial for external connections.

For example, during the first period (A.D. 1200-1250) the non-binarized E-I index is 0.221 and the binarized is -0.189 . This latter number is a product of stronger ties, ties that were created based on a $75 \%$ similarity between proportions of decorated ceramics in the overall ceramic assemblage. This difference of 0.41 in the E-I index between the total number of ties and only the stronger ties (e.g., strong + weak ties versus only strong ties, or strong + weak ties - strong ties $=$ weak ties) demonstrates just how important weak ties were in creating external connections for all of the regions in the analysis prior to the fourth interval (A.D. 1350-1400) and for rooting a region within the larger network. In fact, weak ties are so important for this earlier period that without them (as demonstrated with the binarized E-I scores), the network would appear to be highly disconnected. Following A.D. 1350, the binarized and non-binarized values converge, indicating that it is predominantly the stronger ties that are foundational to the structure of the social network at this time. These strong ties are largely externally focused and appear to be engendered by the inclusive Salado ideology spreading across the southern portion of our study area at this time. As demonstrated, the binarized and non-binarized population level E-I indices reveal a transition from a mix of strong internally focused ties and weak externally focused ties prior to A.D. 1350 to a preponderance of strong externally focused ties in the following periods. Put simply, early in time, weak ties keep a region entwined in the overall network and later in time the strong ties do. 
Additionally, the patterns present at the population, or overall network, level, deviate from previously proposed patterns of social interaction that argue for increasing homophily, a pattern that would necessitate increasing disembeddedness at the network level. Instead, we primarily see an increase in embeddedness at the network level, indicating increasing heterophily through time among archaeological sites. At the critical junction where the period of drought occurs (A.D. 1250-1300), a shift from a focus on weak external ties to maintain embeddedness to a focus on strong external ties to maintain embeddedness is observed. This is dramatically magnified in later periods, possibly as communities in multiple regions focus on expanding social connections through the development of inclusive social institutions that facilitate network embedding. As we will see below, these institutions might be useful in persistence and survival strategies during the environmental downturn.

Differences in E-I indices between various regions (groups) through time illustrate how embeddedness relates to regions that were and were not depopulated across the period considered here (Fig. 3). ${ }^{2}$ In general, our data captures a strong temporal trend where most inwardly focused regions either go through a transition toward greater external focus, such as with the Phoenix Basin, Verde, and Santa Cruz regions, or lose population, as with the Kayenta, Chuska, and Central Arizona Highlands regions. These trends are indications of eventual movement off of the Colorado Plateau during the period considered here for most regions except for Hopi, Puerco West, and Zuni.

The Kayenta, Zuni, Phoenix Basin, Santa Cruz, and Chuska regions were internally focused and disembedded from the overall network during the two periods from A.D. 1200 to 1300 . By the A.D. 1300-1350 interval, however, the Phoenix Basin and Santa Cruz regions had reorganized toward an external focus; the Kayenta and Chuska regions were completely depopulated; and of the original internally focused regions, only Zuni remained. During this third period, three other regions remained settled but shifted in regional focus from external to internal ties: the Verde, Central Arizona Highlands, and San Pedro regions. By the fifth and final interval (A.D. 1400-1450), both the Verde and San Pedro regions once again became externally focused, the Central Arizona Highlands were depopulated, and Safford became internally oriented for the first time. Only Zuni persisted with an internal focus through all five time periods comprising 250 years. Conversely, Hopi, Puerco West, Tonto Basin, Chihuahuan Lowlands, and the Upper Gila regions all persisted with an external focus.

The remaining four regions at this final interval (Phoenix Basin, Safford, Santa Cruz, and San Pedro regions) changed from an internal and an external focus at least once during these 250 years. As argued by previous researchers (e.g., Krackhardt and Stern 1988), our data seem to indicate that regions with many external relationships and, thus more embedded in the network, are more effectively able to persist than those with many internal relationships (less embedded in the network). However, as shown here, embeddedness is not a guarantee of regional persistence. For example, Flagstaff and the Middle Little Colorado regions are always externally oriented and do not persist.

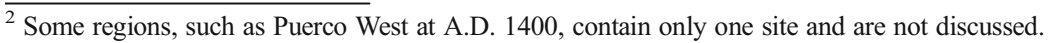




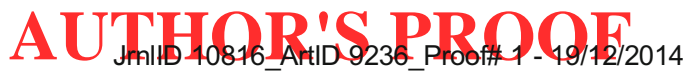

Borck et al.
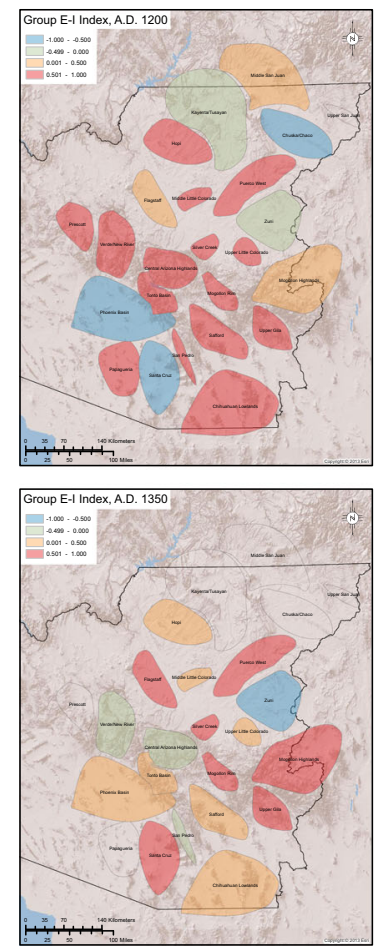
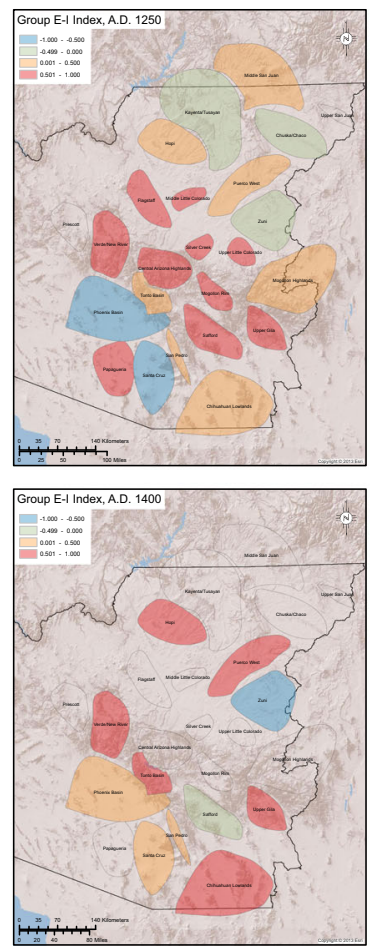
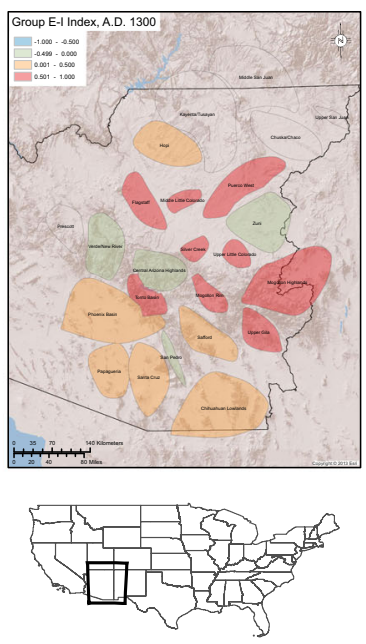

3 Project boundary

Fig. 3 Non-binarized group E-I index through time. External-internal index values through time for all residential sites with ceramic data. The index is calculated on continuous, non-binarized data. Negative values indicate greater within-group proportion of social relations whereas positive values indicate a higher proportion of out-group relationships

But, how much of a region's embeddedness in the network results from stronger $v s$. weaker ties? Archaeologists have argued for the importance of external ties to increase the variability and availability of resources, in particular in contexts marked by high degrees of spatial and temporal resource patchiness (Cordell et al. 2007; Rautman 1993). Further, sociologists have argued that such external ties are most useful during periods of crisis if they are firmly established and strong (Krackhardt and Stern 1988). It would appear then that the ability of a group (region) to weather a crisis relied not simply on external connections, but on strong external connections (e.g., Krackhardt and Stern 1988; Uzzi 1996).

As noted in the population level discussion, the E-I index is traditionally calculated using binary data (see Fig. 4), resulting in an index of strong ties, while the index calculated using non-binary data (see Fig. 3) was composed of both strong and weak ties. Comparing the two figures shows that for many regions in the north as well as some in the south of the research area, such as the Safford region, weak ties were important, albeit moderately so, for maintaining network embeddedness during the A.D. 1200-1250 interval. This happens regardless of the in-group or out-group orientation of their E-I index. The regions along the Mogollon Rim (in the Silver Creek, Mogollon Rim, Central Arizona Highlands regions) primarily relied on strong external connections throughout the temporal span of our study, with one inversion occurring across the entire Rim region during A.D. 1300-1350 when all of these regions relied on 
Are Social Networks Survival Networks?
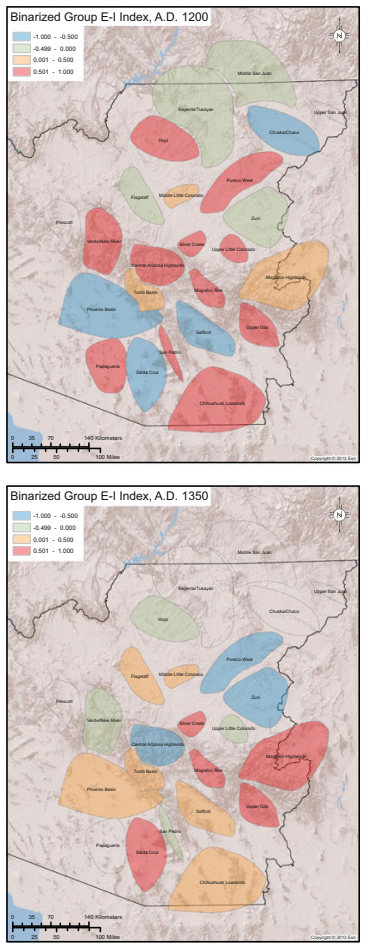
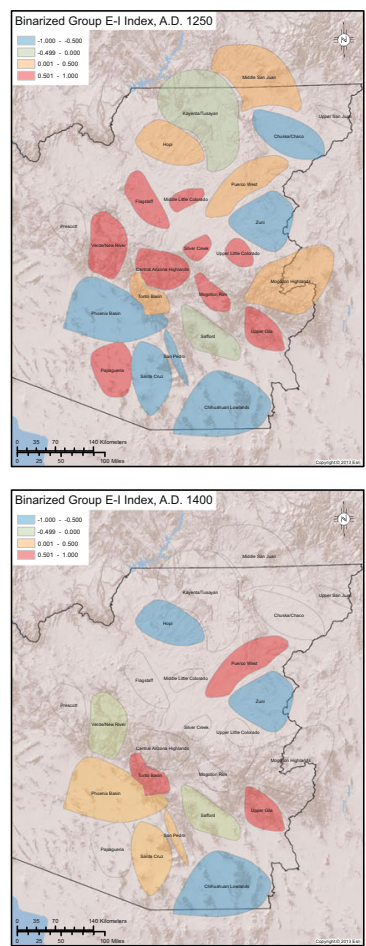
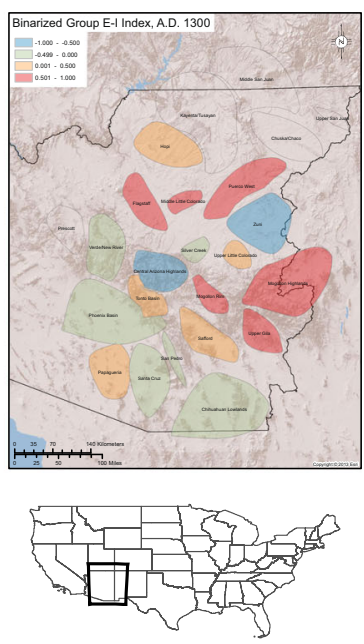

3 Project boundary

Fig. 4 Binarized group E-I index through time. External-internal index values through time for all residential sites with ceramic data. The index is calculated on binarized ties. Negative values indicate greater within-group proportion of social relations whereas positive values indicate a higher proportion of out-group relationships

weak external connections to maintain their embeddedness within the network (although Central Arizona did have an internal focus during this interval). The Hopi region initially contradicted the premise that strong external connections are necessary for regional persistence and instead was marked primarily by weak ties to sites in other regions. Yet, for the period that spans the thirteenth century drought (A.D. 1250-1300), Hopi actually strengthened its external relationships, essentially transitioning from network level embeddedness as a result of many weak ties to embeddedness because of fewer strong ties.

In the northern portion of our study area, the Colorado Plateau, which was depopulated by A.D. 1300, the Hopi and Zuni regions present an interesting comparison. As we discuss further below, both of these regions were consistently among the most densely settled areas in the study area as a whole and particularly in the northern Southwest. Hopi, strongly embedded at the network level through all time periods considered, effectively rode out the environmental crisis. Zuni, on the other hand, was the singular example in our entire study area that was disembedded from other regions in the network and yet managed to sustain large populations in place throughout the periods considered and beyond. The Zuni region's persistence, and the dominance of internal/more local ties provides a possible exception to theories that argue that distant network ties are necessary for weathering resource variability when times become difficult (e.g., Cordell et al. 2007; Rautman 1993). 
Importantly, sociological theorists have argued that, given similar forms of network interaction (i.e., similar levels of embeddedness), groups characterized by larger populations will often be less effective at managing crises (e.g., Krackhardt and Stern 1988, p. 129). In a related vein, Duff (2000, 2002) and others (Nelson et al. 2011; Peeples and Haas 2013) have argued that differences in absolute population create structural differences in the ways that populations interact among themselves and with outsiders. Thus, Duff and others suggest that increased population will often correlate with lower embeddedness, which is consistent with the results presented here (Fig. 5).

Notably, however, our results do not suggest that less embeddedness necessarily correlates with a decline in persistence. The Zuni region is especially interesting in this light. Even more because Zuni persists with a population that fluctuated between the second and ninth highest per 50-year interval — primarily remaining in the top threeand an E-I index that is always indicative of disembeddedness from the rest of the
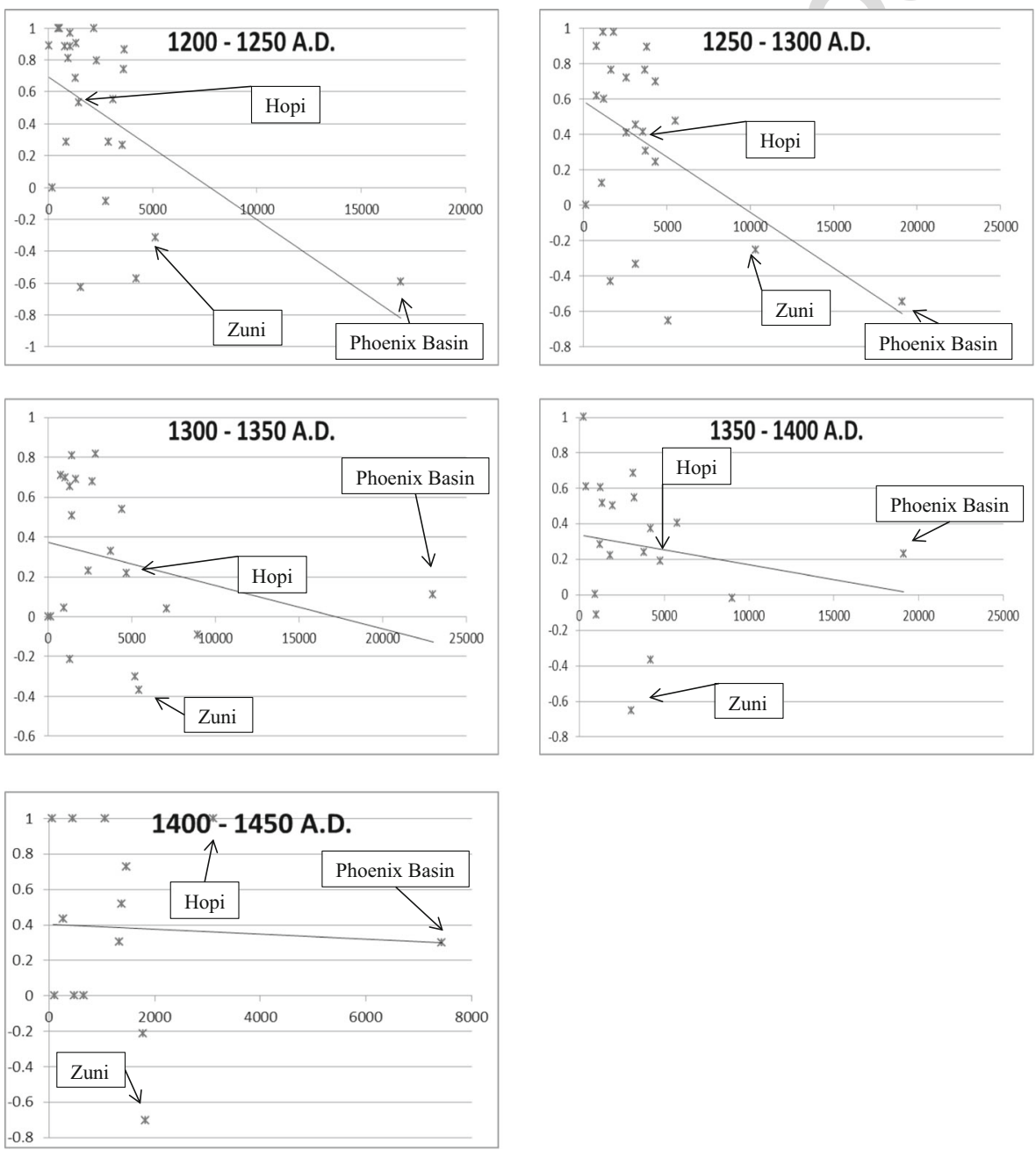

Fig. 5 E-I index to population size through time. Scatterplot time series of E-I index values plotted against the apportioned population in each region as calculated from the Coalescent Communities Database 
network (Fig. 5). We further discuss possible reasons for the apparent exceptional nature of the Zuni region, including potential demographic drivers of such differences, below.

The Phoenix Basin, a clear outlier with a population often more than double any of the next most populous regions (including Hopi, Zuni, and, in a few of the temporal intervals, the Verde region), did not persist much past our final temporal interval. This story is repeated throughout the southern portion of our project area after A.D. 1450. While we end our temporal data for this study with the A.D. 1400-1450 interval for data consistency purposes, our full data set does extend until A.D. 1550. In these later periods, the southern portion of our project area, while still populated (e.g., Bahr 1994), had a dramatic decrease in population and a large-scale social reorganization and spatial dispersion. Thus, large sedentary villages, in the end, were not able to persist in the same manner as Hopi and Zuni. This provides evidence in support of the argument that a larger population is not always beneficial (Krackhardt and Stern 1988).

Hopi, the other region that successfully managed the crisis brought on by the strong drought conditions during A.D. 1276 to 1299 , is not a population outlier, was strongly externally focused, and, like Zuni, exists to this day. Unlike Zuni, though, Hopi meets our expectations that a region is likely to survive in place if they utilize a diverse mix of external connections to help procure resources that may not be available locally during difficult times. Hopi used its external connections, even strengthening them during periods of environmental flux, and while as or more populous than Zuni after A.D. 1300, Hopi had a smaller population during A.D. 1200-1300.

How then were Hopi and Zuni able to persist? Looking first at Zuni, perhaps, the most telling example is the A.D. 1250-1300 interval on Fig. 5. When compared against the previous interval, Zuni experienced a considerable increase in population during a time when much of the Southwest was in the midst of a severe drought. This population jump occurred during the period of greatest upheaval and is an indicator of how the people in the Zuni area responded socially to crises. The Zuni area's higher regional population increased the number of potential internal individuals/communities with which to interact. This likely reduced their dependency on external connections. Furthermore, it appears that instead of merely reacting to the crisis at hand, the Zuni region's increased population in the face of environmental adversity represented a cohesive and long-term social response to crises.

When historically and environmentally contextualized, this population increase likely was beneficial to Zuni for a few reasons. Unlike their similarly disembedded neighbors, Zuni had a high degree of internal residential mobility and an extremely flexible settlement system (Schachner 2012). Additionally, they were positioned along a gradient in the Southwest where changes in precipitation patterns between summer dominant and summer and winter (bimodal) precipitation patterns were common. As such, they would have had to develop practices well adapted to considerable environmental variability and would have had access to areas marked by local spatial and temporal variability (Hegmon et al. 2014). These practices included a flexible settlement and an agricultural system with frequent community relocations (Peeples 2011; Schachner 2012) as well as a dispersal of communities across the landscape to take advantage of a diverse local environment marked by temporal and spatial variability that was considerable, even by Southwestern standards (Dean 2007). It would appear, then, that given flexible resources and a larger population dispersed across the 
landscape, groups that are highly disembedded at the network level can persist. Beyond this, the Zuni region also appears to have been characterized by flexibility in social organization. As Cameron and Duff (2008) note, unlike many other portions of the northern Southwest, leadership and social organization in the Zuni region during the period considered here appear to have been decidedly local in nature instead of relying heavily on political referents that were distant in space and time (in particular, developments associated with the Chaco Phenomenon and its prodigies which continued to structure community organization across much of the north during the thirteenth century). Cameron and Duff (2008, p. 51) argue that the local focus of power in the Zuni region allowed leaders to create and maintain tighter social ties among larger groups of people locally, ultimately resulting in the establishment of large towns that appear to have further enhanced regional stability.

The continued success of Zuni and Hopi with dramatically different levels of embeddedness, but similar success throughout the long period considered here, highlights a few key points. Many economic and sociological examinations of network embeddedness frequently rely on synchronic data (but, see Brass et al. 2004 and Powell et al. 2005 for good examples of the use of longitudinal data). However, the fluctuations between a focus on internal and external social relationships in the E-I index for some regions (e.g., Safford) demonstrate that these static snapshots of data are not good predictors of a region's ability to manage a crisis since the ratio of the internal and external connections may fluctuate through time. This fluctuation may occur as people within regions struggle with and create social coping mechanisms for environmental crises (which is another good reason to prefer diachronic data for this index since social groups actually respond to crises instead of simply continuing failing practices) or immigrate to a region along extant connections (Clark and Lyons 2012; Clark 2001; Franklin and Masse 1976; Lyons 2003).

This study also highlights an important difference between archaeological data and some economic and sociological data (see Xiao and Tsui 2007 for an example of researchers overcoming this shortcoming) in that it examines societies that are not functioning according to the cultural logic of Western industrialized nations. As various researchers have demonstrated (e.g., Peeples and Haas 2013; Xiao and Tsui 2007), there are important cultural differences in the ways in which social relationships are created and valued. These differences may lead to contradictions when expectations generated in one society are applied to another. Further studies besides those already mentioned (Mills et al. 2013a, c; Peeples and Haas 2013) would be useful in determining alternative social processes that may have been affecting persistence during the late pre-Hispanic period in the American Southwest in addition to fluctuating trends of homophily and heterophily.

In sum, for the E-I index, it appears that while groups with an externally oriented social network are not necessarily good predictors of persistence (since many externally focused groups did not successfully manage the crisis brought on by the thirteenth century drought), consistently internally focused groups are a good predictor of depopulation events (see Borck 2012 for an example outside of this study area). That is, of course, unless they are able to counter-balance this internal focus with a sufficiently high population level to maintain viable communities that are dispersed across a locally variable and productive landscape. This study also demonstrates that there can be many paths that ultimately lead toward regional stability, whether through 
Are Social Networks Survival Networks?

network embeddedness or dis-embeddedness, and each case should be historically contextualized to examine how it fits within the larger framework.

\section{Conclusion}

Krackhardt and Stern (1988) created an index of social interactions that is flexible in how it can be applied by social scientists, as we and Everett and Borgatti (2012) have demonstrated with two different applications of the E-I index. While Everett and Borgatti focused on the various ways researchers can manipulate the E-I index to examine centrality, in this article, we have focused on a few ways that the E-I index can be modified for examining archaeological data.

Applying the E-I index to social network data from the North American Southwest during the late prehispanic period has generated a number of interesting results. First, a primarily external orientation in social relationships seems to be necessary in most instances for regions to successfully persist in the face of an environmental crisis, which in this case was a severe drought from A.D. 1276-1299. Most regions fit this prediction. Yet, this high proportion of out-group relationships does not guarantee survival in place through the crisis or long-term persistence in general. Many regions in our study area were depopulated (Hill et al. 2004) regardless of whether they had an internal (disembedded) or external (embedded) focus. It does however highlight which regions were more likely to weather a crisis. A high proportion of external relationships are a good predictor for regions that will persist. In other words, regions that are embedded within the larger network do better during difficult times than disembedded regions. This is especially true if the disembedded regions have low population levels.

Further, in examining the strength of external connections, it became clear that while many regions depended on weak ties to maintain their external connections, the relative reliance on strong external ties increased during times of stress. Thus, the inhabitants of some regions strengthened their connections to other regions, possibly in an effort to ensure that their support network would be less easily unraveled during precarious times. What is more, it appears that a mixed reliance on stronger and weaker external ties is common and more beneficial to a region's persistence (following Uzzi 1996) than relying on either alone. Hopi's sudden increase in stronger external ties during the late thirteenth century drought, and the associated demographic downturns throughout much of the project area, might indicate that strong external ties are better for managing severe crises. Applying the E-I index to archaeological data reveals that, at least in our study area, external relationships are best if they are a flexible mix of weaker and stronger connections that allow for an increase in strong external ties when necessary.

The internal focus in the Zuni region is an exception. Zuni, disembedded from the overall network and with a higher population than most regions, persisted through the turbulent late prehispanic period and even through Spanish colonialism. Like Hopi, this region is still inhabited today. Yet, other regions in our study with similar E-I indices do not have this level of continuity. So, it appears that having a high population, at least when a group is internally oriented, might be beneficial when adequate resources are available and the population is distributed across the landscape. This is possibly a unique historical and environmental case where Zuni, already practicing short-term, short-distance community mobility to take advantage of changing niches of 
productivity in an environmentally diverse region, increased their population to exploit this variability. Zuni also demonstrates why thinking about persistence at a regional level may be more beneficial than at a site level. This reframing of persistence, or maybe restructuring the scale at which we examine persistence, is supported by our research as well as previous research in the North American Southwest (e.g., Duff 1998; Herr and Clark 1997).

Earlier sociological investigations have indicated that there is a general trend toward closure (homophily) and thus network level disembeddedness in social relationships. However, our data indicate that this is not always the case. Instead, we perceive multiple fluctuations in the trend toward lesser and greater homophily, a process that might be better thought of as a network dialectic. As relations approach socially or environmentally unsupportable levels of embeddedness or disembeddedness, they rework themselves into a more stable configuration. Homophily research has used many common proverbs as a focus for its findings, such as "birds of a feather flock together." This can be compared with "opposites attract" and then contradicted as "opposites attract, but like-minded last." Our research indicates that settlements with heterophilous connections to communities outside their region are the ones that are most likely to persist in place following an environmental downturn. Hence, taking advantage of the attraction of the opposites helps groups endure crises.

Additionally, an interesting pattern emerges throughout many of the temporal intervals of our study. The groups that were used to calculate the E-I index were created based primarily on geography, hydrology, and archaeological data. As expected, based on a review of much of the current literature on space and social networks (e.g., Allen 1977; Krackhardt 1994; Mills et al. 2013a), spatial propinquity was a strong force driving the interactions of regions and settlements. However, during the later periods of our analysis, long-distance ties across the network strongly interlinked a number of regions, creating an embedded network, even while some, such as Hopi, were spatially isolated.

Social network research is a fertile ground for methodological and theoretical innovations in the interpretation of cultural data. So, it is no surprise that archaeologists have started to use network analyses to examine our data in new ways, allowing increasing insights into the human past. For our analysis, we were able to examine how ancient groups reacted to the crisis of a prolonged drought in the late thirteenth century. Even more, as this enhances our understanding of how differing groups respond to emergencies, there is applicability for how we can manage modern crises. Modern research is building a case that our ability to connect and interact socially may be as important as or more important than our individual cognitive abilities (Dunbar 1998; Gao et al. 2009; Herrmann et al. 2007). Social networks may then be one of the most significant means that humans have in order to overcome social and environmental problems. This is true in the modern world (McMahan 2013; Suter et al. 2009), and as our research demonstrates, it was true in the late pre-Hispanic Southwest. Using SNA on archaeological data allows us to evaluate contemporary decision making strategies and create a framework for response that has been demonstrated to be effective in the past. Thus, understanding how humans have manipulated networks in the past can lead to very clear insights on how humans could mobilize different types of social connections during present day crises.

Yet, for all the benefits of incorporating social network method and theory, as archaeological researchers, we do need to exercise caution. While SNA methods are 
sound, much of social network theory has been built on data primarily from Western industrialized nations. While this could be viewed as a problematic bias built into the theory, in reality, it leaves us with a dramatic number of theoretical paradigms that archaeologists can test using our diachronic and cross-cultural data. Archaeological case studies may produce alternative outcomes to the sociological and economic literature, which can only enhance our understanding of how humans react and interact to various social and environmental pressures.

Finally, the application of SNA to archaeological data should not be viewed in a similar manner to the influx of theory from other disciplines that has often occurred in archaeology's past. Instead, the application of SNA to archaeological data should be regarded as an area ripe for the chance of cross-fertilization, an arena where archaeologists examine ideas gathered from sociologists, economists, and political scientists and then test them against our data source to see just how robust these theories are in terms of culture and time. Archaeologists are poised to create new theory while applying SNA to longitudinal data captured from non-Western, or at least non-industrialized peoples. This process has obviously already begun as current research and the other articles in this special issue demonstrate (Blake 2014; Brughmans 2010; Collar 2013; Coward 2010; Knappett 2013; Mills et al. 2013a, c; Peeples and Haas 2013).

Acknowledgments This study was funded in part by National Science Foundation Human and Social Dynamics Program Awards 0827007 (to Barbara J. Mills) and 0827011 (to Jeffery J. Clark). Additionally, the authors would like to thank Joseph Galaskiewicz as well as our fellow members of the Southwest Social Network Projects School of Advance Research NSF Working Group Seminar (W. Randall Haas, Jr., Deborah Huntley, Aaron Clauset, Ronald Breiger, John M. Roberts, Jr., M. Steven Shackley, and J. Brett Hill), for commenting on earlier versions of this article.

\section{References}

Allen, T. J. (1977). Managing the flow of technology: Technology transfer and the dissemination of technological information within the research and development organization. Cambridge: MIT Press.

Anthony, D. W. (1990). Migration in archeology: the baby and the bathwater. American Anthropologist, 92(4), 895-914.

Bahr, D. M. (1994). The short, swift time of gods on earth: The Hohokam chronicles. Berkeley: University of California Press.

Blake, E. (2014). Social networks and regional identity in Bronze Age Italy. Cambridge: Cambridge University Press.

Borck, L. (2012). Patterns of resistance: violence, migration, and trade in the Gallina heartland (Master's Thesis). University of Arizona, Tucson.

Borgatti, S. P., Everett, M. G., \& Freeman, L. C. (2002). Ucinet for Windows: Software for social network analysis. Harvard: Analytic Technologies.

Borgatti, S. P., \& Halgin, D. S. (2011). On network theory. Organization Science, 22(5), 1168-1181.

Brainerd, G. W. (1951). The place of chronological ordering in archaeological analysis. American Antiquity, 16(4), 301-313.

Brass, D. J., Galaskiewicz, J., Greve, H. R., \& Tsai, W. (2004). Taking stock of networks and organizations: a multilevel perspective. Academy of Management Journal, 47(6), 795-817.

Brughmans, T. (2010). Connecting the dots: towards archaeological network analysis. Oxford Journal of Archaeology, 29(3), 277-303.

Burt, R. S. (1991). Measuring age as a structural concept. Social Networks, 13(1), 1-34. 
Cameron, C. M. (2013). How people moved among ancient societies: broadening the view. American Anthropologist, 115(2), 218-231.

Cameron, C. M., \& Duff, A. I. (2008). History and process in village formation: context and contrasts from the northern Southwest. American Antiquity, 73(1), 29-57.

Carrington, P., Scott, J., \& Wasserman, S. (2005). Models and methods in social network analysis. Cambridge: Cambridge University Press.

Clark, J. J. (2001). Tracking prehistoric migrations: Pueblo settlers among the Tonto Basin Hohokam. Tucson: University of Arizona Press.

Clark, J. J., \& Lyons, P. D. (Eds.). (2012). Migrants and mounds:lLate prehistoric archaeology of the Lower San Pedro Valley. Tucson: Archaeology Southwest. Anthropological Papers No. 45.

Collar, A. (2013). Re-thinking Jewish ethnicity through social network analysis. In C. Knappett (Ed.), Network analysis in archaeology: New approaches to regional interaction (pp. 223-246). Oxford: Oxford University Press.

Colson, E. (1979). The Harvey Lecture Series. In good years and in bad: food strategies of self-reliant societies. Journal of Anthropological Research, 35(1), 18-29.

Cordell, L. S., West, C. R. V., Dean, J. S., \& Muenchrath, D. A. (2007). Mesa Verde settlement history and relocation: climate change, social networks, and Ancestral Pueblo migration. Kiva, 72(4), 379-405.

Coward, F. (2010). Small worlds, material culture and ancient Near Eastern social networks. Proceedings of the British Academy, 158, 453-484.

Crown, P. L. (1994). Ceramics and ideology: Salado Polychrome pottery. Albuquerque: University of New Mexico Press.

Dean, J. S. (Ed.). (2000). Salado. Albuquerque: University of New Mexico Press.

Dean, J. S. (2007). Zuni area paleoenvironment. In D. A. Gregory \& D. Wilcox (Eds.), Zuni origins: Toward a new synthesis of Southwestern archaeology (pp. 77-94). Tucson: University of Arizona Press.

Diamond, J. (2005). Collapse: How societies choose to fail or succeed (revisedth ed.). New York: Viking.

Duff, A. (1998). The process of migration in the late prehistoric Southwest. In K. A. Spielmann (Ed.), Migration and reorganization: The Pueblo IV period in the American Southwest (pp. 31-52). Tempe: Arizona State University. ASU Anthropological Papers 51.

Duff, A. (2000). Scale, interaction, and regional analysis in late Pueblo prehistory. In M. Hegmon (Ed.), The archaeology of regional interaction: Religion, warfare, and exchange across the American Southwest (pp. 51-71). Boulder: University of Press of Colorado.

Duff, A. (2002). Western Pueblo identities: Regional interaction, migration, and transformation. Tucson: University of Arizona Press.

Dunbar, R. I. (1998). The social brain hypothesis. Brain, 9(10), 178-190.

Dyson-Hudson, R., \& Smith, E. A. (1978). Human territoriality: an ecological reassessment. American Anthropologist, 80(1), 21-41.

Everett, M. G., \& Borgatti, S. P. (2012). Categorical attribute based centrality: E-I and G-F centrality. Social Networks, 34(4), 562-569.

Franklin, H. H., \& Masse, W. B. (1976). The San Pedro Salado: a case of prehistoric migration. Kiva, 42(1), 47-55.

Galaskiewicz, J. (1979). Exchange networks and community politics. Beverly Hills: Sage Publications.

Gao, W., Zhu, H., Giovanello, K. S., Smith, J. K., Shen, D., Gilmore, J. H., \& Lin, W. (2009). Evidence on the emergence of the brain's default network from 2-week-old to 2-year-old healthy pediatric subjects. Proceedings of the National Academy of Sciences, 106(16), 6790-6795.

Gimeno, J. (2004). Competition within and between networks: the contingent effect of competitive embeddedness on alliance formation. Academy of Management Journal, 47(6), 820842 .

Glowacki, D. M. (2010). The social and cultural contexts of the Central Mesa Verde region during the thirteenth century migrations. In T. A. Kohler, M. D. Varien, \& A. M. Wright (Eds.), Leaving Mesa Verde: Peril and change in the thirteenth-century Southwest (pp. 200-221). Tucson: University of Arizona Press.

Golitko, M., Meierhoff, J., Feinman, G. M., \& Williams, P. R. (2012). Complexities of collapse: the evidence of Maya obsidian as revealed by social network graphical analysis. Antiquity, 86(332), 507-523.

Golub, B., \& Jackson, M. O. (2012). How homophily affects the speed of learning and best-response dynamics. The Quarterly Journal of Economics, 127(3), 1287-1338.

Granovetter, M. (1985). Economic action and social structure: the problem of embeddedness. The American Journal of Sociology, 91(3), 481-510.

Halstead, P., \& O’Shea, J. (1989). Introduction. In P. Halstead \& J. O’Shea (Eds.), Bad year economics: Cultural responses to risk and uncertainty (pp. 1-5). Cambridge: Cambridge University Press. 
Are Social Networks Survival Networks?

Hanneman, R. A., \& Riddle, M. (2005). Introduction to social network methods. Riverside (published in digital form at http://faculty.ucr.edu/ hanneman/): University of California. Retrieved from http://faculty. ucr.edu/ hanneman/nettext/Introduction_to_Social_Network_Methods.pdf.

Hart, J., \& Engelbrecht, W. (2012). Northern Iroquoian ethnic evolution: a social network analysis. Journal of Archaeological Method and Theory, 19(2), 322-349.

Haury, E. W. (1976). Salado: the view from Point of Pines. Kiva, 42(1), 81-84.

Hegmon, M., Arneborg, J., Comeau, L., Dugmore, C. A. J., Hambrecht, G., Ingram, S., Kintigh, K. W., McGovern, T. H., Nelson, M. C., Peeples, M. A., Simpson, I., Spielmann, K., Streeter, R., \& Vesteinsson, O. (2014). The human experience of social change and continuity: The Southwest and North Atlantic in "interesting times" ca. 1300. In S. Kulyk, C. Tremain, \& M. Sawyer (Eds.), Climates of change: The shifting environments of archaeology (pp. 53-68). Calgary: University of Calgary Press. Proceedings of the 44th annual Chacmool conference.

Hegmon, M., Nelson, M. C., \& Ruth, S. M. (1998). Abandonment and reorganization in the Mimbres region of the American Southwest. American Anthropologist, 100(1), 148-162.

Herr, S., \& Clark, J. J. (1997). Patterns in the pathways: early historic migrations in the Rio Grande Pueblos. Kiva, 62(4), 365-390.

Herrmann, E., Call, J., Hernàndez-Lloreda, M. V., Hare, B., \& Tomasello, M. (2007). Humans have evolved specialized skills of social cognition: the cultural intelligence hypothesis. Science, 317(5843), 1360-1366.

Hess, M. (2004). "Spatial” relationships? Towards a reconceptualization of embeddedness. Progress in Human Geography, 28(2), 165-186.

Hill, J. B., Clark, J. J., Doelle, W. H., \& Lyons, P. D. (2004). Prehistoric demography in the Southwest: migration, coalescence, and Hohokam population decline. American Antiquity, 69(4), 689-716.

Hill, J. B., Clark, J. J., Doelle, W. H., \& Lyons, P. D. (2010). Depopulation of the northern Southwest: A macroregional perspective. In T. A. Kohler, M. D. Varien, \& A. M. Wright (Eds.), Leaving Mesa Verde: Peril and change in the thirteenth-century Southwest (pp. 34-53). Tucson: University of Arizona Press.

Hill, J. B., Wilcox, D. R., Doelle, W. H., \& Robinson, W. J. (2012). Coalescent Communities GIS Database Version 2.0: Archaeology Southwest, Museum of Northern Arizona. Unpublished MS, Archaeology Southwest, Tucson.

Holling, C. S. (1973). Resilience and stability of ecological systems. Annual Review of Ecology and Systematics, 4, 1-23.

Holling, C. S., \& Gunderson, L. H. (2002). Resilience and adaptive cycles. In L. H. Gunderson \& C. S. Holling (Eds.), Panarchy: Understanding transformations in human and natural systems (pp. 25-62). Washington: Island Press.

Kaldahl, E. J., Van Keuren, S., \& Mills, B. J. (2004). Migration, factionalism, and the trajectories of Pueblo IV period clusters in the Mogollon Rim region. In E. C. Adams \& A. I. Duff (Eds.), The protohistoric Pueblo world, A.D. 1275-1600 (pp. 85-94). Tucson: University of Arizona Press.

Knappett, C. (Ed.). (2013). Network analysis in archaeology: New approaches to regional interaction. Oxford: Oxford University Press.

Kohler, T. A. (2010). A new paleoproductivity reconstruction for southwestern Colorado, and its implications for understanding thirteenth-century depopulation. In T. A. Kohler, M. D. Varien, \& A. M. Wright (Eds.), Leaving Mesa Verde: Peril and change in the thirteenth-century Southwest (pp. 75-101). Tucson: University of Arizona Press.

Kohler, T. A., Varien, M. D., \& Wright, A. M. (Eds.). (2010). Leaving Mesa Verde: Peril and change in the thirteenth-century Southwest. Tucson: University of Arizona Press.

Krackhardt, D. (1994). Constraints on the interactive organization as an ideal type. In C. C. Heckscher \& A. Donnellon (Eds.), The post-bureaucratic organization: New perspectives on organizational change (pp. 211-222). Thousand Oaks: Sage Publications.

Krackhardt, D., \& Stern, R. N. (1988). Informal networks and organizational crises: an experimental simulation. Social Psychology Quarterly, 51(2), 123-140.

Kuckelman, K. A., Lightfoot, R. R., \& Martin, D. L. (2002). The bioarchaeology and taphonomy of violence at Castle Rock and Sand Canyon Pueblos, Southwestern Colorado. American Antiquity, 67(3), 486-513.

Kuckelman, K. A., \& Martin, D. L. (2012). Taphonomy and warfare in the Mesa Verde region. Landscapes of Violence, 2(2), Article 13.

Laumann, E. O. (1966). Prestige and association in an urban community: An analysis of an urban stratification system. Indianapolis and New York: Bobbs-Merrill.

Lazarsfeld, P. F., \& Merton, R. K. (1954). Friendship as a social process: a substantive and methodological analysis. Freedom and Control in Modern Society, 18(1), 18-66.

Lekson, S. H. (2002). Salado archaeology of the Upper Gila, New Mexico. Tucson: University of Arizona Press. Anthropological Papers of the University of Arizona No. 67. 
Lyons, P. D. (2003). Ancestral Hopi migrations. Tucson: University of Arizona Press. Anthropological Papers of the University of Arizona No. 68.

Marsden, P. V. (1988). Homogeneity in confiding relations. Social Networks, 10(1), 57-76.

Martin, R. (1994). Economic theory and human geography. In D. Gregory, R. Martin, \& G. Smith (Eds.), Human geography: Society, space and social science (pp. 21-53). Minneapolis: University of Minnesota Press.

McAnany, P. A., \& Yoffee, N. (Eds.). (2010). Questioning collapse: Human resilience, ecological vulnerability, and the aftermath of empire. Cambridge: Cambridge University Press.

McMahan, B. (2013). Risk, luck, and resiliency: hurricanes and disaster in the dynamic environment of the US Gulf Coast (Ph.D. dissertation). University of Arizona, Tucson.

McPherson, J. M., \& Smith-Lovin, L. (1987). Homophily in voluntary organizations: status distance and the composition of face-to-face groups. American Sociological Review, 52(3), 370-379.

McPherson, J. M., Smith-Lovin, L., \& Cook, J. M. (2001). Birds of a feather: homophily in social networks. Annual Review of Sociology, 27, 415-444.

Middleton, G. D. (2012). Nothing lasts forever: environmental discourses on the collapse of past societies. Journal of Archaeological Research, 20(3), 257-307.

Mills, B. J. (2007). Multicrafting, migration, and identity in the American Southwest. In I. Shimada (Ed.), Craft Production in Complex Societies (pp. 25-43). Salt Lake City: University of Utah Press.

Mills, B. J., Clark, J. J., Peeples, M. A., Haas, W. R., Roberts, J. M., Hill, J. B., Huntley, D. L., Borck, L., Breiger, R. L., Clauset, A., \& Shackley, M. S. (2013a). Transformation of social networks in the late preHispanic US Southwest. Proceedings of the National Academy of Sciences, 110(15), 5785-5790.

Mills, B. J., Clark, J. J., Peeples, M. A., Haas, W. R., Roberts, J. M., Hill, J. B., Huntley, D. L., Borck, L., Breiger, R. L., Clauset, A., \& Shackley, M. S. (2013b). Transformation of social networks in the late preHispanic US Southwest (supplemental material). Proceedings of the National Academy of Sciences, $110(15)$.

Mills, B. J., \& Crown, P. L. (1995). Ceramic production in the American Southwest: An introduction. In B. J. Mills \& P. L. Crown (Eds.), Ceramic production in the American Southwest (pp. 1-29). Tucson: University of Arizona Press.

Mills, B. J., Herr, S. A., \& Van Keuren, S. (Eds.). (1999). Living on the edge of the rim: Excavations and analysis of the Silver Creek Archaeological Research Project, 1993-1998. Tucson: University of Arizona. Arizona State Museum Archaeological Series No. 192.

Mills, B. J., Peeples, M. A., Haas, Jr., W. R., Borck, L., Clark, J. J., \& Roberts, Jr., J. M. (2015). Multiscalar perspectives on social networks in the prehispanic Southwest. American Antiquity, $80(1)$, (in press).

Mills, B. J., Roberts, J. M., Clark, J. J., Haas, W. R., Huntley, D., Peeples, M. A., Borck, L., Ryan, S. C., Trowbridge, M., \& Breiger, R. L. (2013c). The dynamics of social networks in the Late Prehispanic U.S. Southwest. In C. Knappett (Ed.), Network analysis in archaeology: New approaches to regional interaction (pp. 181-202). Oxford: Oxford University Press.

Minnis, P. E. (1985). Social adaptation to food stress: A prehistoric southwestern example. Chicago: University of Chicago Press.

Nelson, M. C., Kulow, S., Peeples, M. A., Hegmon, M., \& Kinzig, A. P. (2011). Resisting diversity in small scale societies: a long-term archaeological study. Ecology and Society, 16(1), article 25.

Newman, M. (2009). Networks: An introduction. Oxford: Oxford University Press.

Newman, M., Barabási, A.-L., \& Watts, D. J. (2006). The structure and dynamics of networks. Princeton: Princeton University Press.

Opsahl, T., Agneessens, F., \& Skvoretz, J. (2010). Node centrality in weighted networks: generalizing degree and shortest paths. Social Networks, 32(3), 245-251.

Peeples, M. A. (2011). Identity and social transformation in the prehispanic Cibola world: A.D. 1150-1325. (Ph.D. dissertation). Arizona State University, Tempe.

Peeples, M. A., \& Haas, W. R. (2013). Brokerage and social capital in the prehispanic U.S. Southwest. American Anthropologist, 115(2), 232-247.

Peeples, M. A., Mills, B. J., Roberts, Jr. J. M., Clark, J. J., \& Haas, Jr., W. R. (2014). Analytical issues in the application of network analyses to archaeology. In Brughmans, T., Coward, F., and Collar, A. (Eds.), The connected past: challenging networks in archaeology and history. Oxford University Press, Oxford, in press.

Peeples, M. A., \& Roberts, J. M. (2013). To binarize or not to binarize: Relational data and the construction of archaeological networks. Journal of Archaeological Science, 40(7), 3001-3010.

Polanyi, K. (2001). The great transformation: The political and economic origins of our time. Boston: Boston Press.

901

902

903

904

905

906

907

908

909

910

911

912

913

914

915

916

917

918

919

920

921

922

923

924

925

926

927

928

929

930

931

$932 \mathrm{Q} 8$

933

934

935

936

937

938

939

940

941

942

943

944

945

946

947

948

949

950

951

952Q9

953

954

955

956

957

958

959 
Are Social Networks Survival Networks?

Powell, W. W., White, D. R., Koput, K. W., \& Owen-Smith, J. (2005). Network dynamics and field evolution: the growth of interorganizational collaboration in the life sciences. American Journal of Sociology, 110(4), $1132-1205$.

Rautman, A. (1993). Resource variability, risk, and the structure of social networks: an example from the prehistoric Southwest. American Antiquity, 58(3), 403-424.

Redman, C. L. (2005). Resilience theory in archaeology. American Anthropologist, 107(1), 70-77.

Roberts, J. M., Mills, B. J., Clark, J. J., Haas, W. R., Huntley, D. L., \& Trowbridge, M. A. (2012). A method for chronological apportioning of ceramic assemblages. Journal of Archaeological Science, 39(5), 15131520 .

Robinson, W. S. (1951). A method for chronologically ordering archaeological deposits. American Antiquity, 16(4), 293-301.

Saunders, C. (2007). Using social network analysis to explore social movements: a relational approach. Social Movement Studies, 6(3), 227-243.

Schachner, G. (2012). Population circulation and the transformation of ancient Zuni communities. Tucson: University of Arizona Press.

Scott, J. (2000). Social network analysis: A handbook (2nd ed.). Los Angeles: Sage.

Shaw, G. B. (1988). Pygmalion. Harmondsworth: Penguin.

Somers, M. R. (1994). The narrative constitution of identity: a relational and network approach. Theory and Society, 23(5), 605-649.

Stark, M. T., \& Heidke, J. M. (1998). Ceramic manufacture, productive specialization, and the Early Classic period in Arizona's Tonto Basin. Journal of Anthropological Research, 54(4), 497-517.

Suter, L., Birkland, T., \& Larter, R. (2009). Disaster research and social network analysis: examples of the scientific understanding of human dynamics at the National Science Foundation. Population Research and Policy Review, 28(1), 1-10.

Uzzi, B. (1996). The sources and consequences of embeddedness for the economic performance of organizations: the network effect. American Sociological Review, 61(4), 674-698.

Uzzi, B. (1997). Social structure and competition in interfirm networks: the paradox of embeddedness. Administrative Science Quarterly, 42(1), 35-67.

Van West, C. R. (1994). Reports of Investigations No. 67. Pullman: Department of Anthropology, Washington State University and Cortez: Crow Canyon Archaeological Center.

Varien, M. D. (1999). Sedentism and mobility in a social landscape: Mesa Verde and beyond. Tucson: University of Arizona Press.

Verbrugge, L. M. (1977). The structure of adult friendship choices. Social Forces, 56(2), 576-597.

Wasserman, S., \& Faust, K. (1994). Social network analysis: Methods and applications. Cambridge: Cambridge University Press.

Wiessner, P. (1977). Hxaro: A regional system of reciprocity for reducing risk among the !Kung Bushmen (Ph.D. Dissertation). University of Michigan, Ann Arbor.

Wilcox, D. R., Doelle, W. H., Hill, J. B., \& Holmlund, J. P. (2003). Coalescent Communities GIS Database: Museum of Northern Arizona, Center for Desert Archaeology, GeoMap Inc. Tucson: Center for Desert Archaeology.

Wilcox, M. (2009). The Pueblo Revolt and the mythology of conquest: An indigenous archaeology of contact. Berkeley: University of California Press.

Wright, A. M. (2010). The climate of the depopulation of the northern Southwest. In T. A. Kohler, M. D. Varien, \& A. M. Wright (Eds.), Leaving Mesa Verde: Peril and change in the thirteenth-century Southwest (pp. 75-101). Tucson: University of Arizona Press.

Xiao, Z., \& Tsui, A. S. (2007). When brokers may not work: the cultural contingency of social capital in Chinese high-tech firms. Administrative Science Quarterly, 52(1), 1-31.

960

961

962

963

964

965

966

967

968

969

970

971

972

973

974

975

976

977

978

979

980

981

982

983

984

985

986

987

988

989

990

991

992

993

994

995

996

997

998

999

1000

1001

1002

1003

1004

1005

1006

1007 


\section{AUTHOR QUERIES}

\section{AUTHOR PLEASE ANSWER ALL QUERIES.}

Q1. Please check the suggested running page title if appropriate.

Otherwise, please provide short running title with maximum of 65 characters including spaces.

Q2. Please check captured corresponding email address if correct.

Q3. "Ahlstrom et al. 1995" is cited in text but not given in the reference list. Please provide details in the list.

Q4. "Billman et al. 2000" is cited in text but not given in the reference list. Please provide details in the list .

Q5. Please check if the captured figure captions are correct.

Q6. Please check if the captured Table 1 caption is correct.

Q7. Kohler et al. (2010) was not cited anywhere in the text. Please provide a citation. Alternatively, delete the item from the list.

Q8. Please provide updated information. If possible, please advise the DOI number if this reference is still for publication or in press.

Q9. Please provide updated information. If possible, please advise the DOI number if this reference is still for publication or in press. 